\title{
Experimental evidence for the role of calcium in eggshell pigmentation pattern and breeding performance in Blue Tits Cyanistes caeruleus
}

\author{
Vicente García-Navas • Juan José Sanz • Santiago Merino • \\ Josué Martínez-de la Puente · Elisa Lobato · Sara del Cerro • \\ Juan Rivero · Rafael Ruiz de Castañ eda · Juan Moreno
}

\begin{abstract}
Previous studies have found strong relationships between calcium availability and eggshell pigmentation in the Great Tit (Parus major). According to the "structural function hypothesis", protoporphyrins, the pigments responsible for reddish spots on speckled eggs, are deposited in those areas of the shell where calcium deposition is less intense. In the study reported here, which was carried out in three Blue Tit (Cyanistes caeruleus) populations in central Spain, we provide partial experimental support for the association between protoporphyrin eggshell pigmentation and shell thinning. Contrary to our expectations, we did not observe a decrease in the size and intensity of pigment spots for those eggs from calciumsupplemented nests. However, we did find that the provision of calcium-rich material during the egg-laying period led to a more wide distribution of pigment spots and reduced the proportion of eggs with defective shells (deviant pigmentation, dull and rough surface). When only the supplemented nests were considered in the analysis, within the same clutch we also detected differences in the spotting distribution between those eggs laid by female
\end{abstract}

Communicated by F. Bairlein.

V. García-Navas J. J. Sanz S. Merino

J. Martínez-de la Puente E. Lobato S. del Cerro J. Rivero

R. Ruiz de Castañeda J. Moreno

Departamento de Ecología Evolutiva, Museo Nacional

de Ciencias Naturales (CSIC), Calle José Gutiérrez Abascal,

2, 28006 Madrid, Spain

Present Address:

V. García-Navas (\&) J. J. Sanz

Departamento de Ciencias Ambientales, Facultad de Medio

Ambiente, Universidad de Castilla-La Mancha,

Avenida Carlos III s/n., 45071 Toledo, Spain

e-mail: vicente.garcianavas@uclm.es
Blue Tits observed to have consumed calcium consumption on the day prior to laying and those observed not to have consumed calcium on the day prior to laying. Clutch size was not affected by the calcium supplementation. Female Blue Tits experimentally supplied with calcium-rich material had a shorter incubation period than control females, and they laid eggs with thicker shells. Eggshell thickness markedly affects the probability of hatching and could explain the lower proportion of unhatched late eggs found in supplemented nests in comparison with control ones. This study highlights the role of calcium in eggshell maculation and its effects on breeding performance of small passerines. We found the spotting distribution to be a good predictor of calcium deficiency. However, our results provide only mixed support for the "structural function hypothesis": in our study populations, the thickness of the eggshell was intimately associated with calcium availability, but the relationship between calcium and protoporphyrin deposition remains far from clear.

Keywords Blue Tit Calcium availability Eggshell pigmentation Maculation Speckled eggs

\section{Introduction}

Avian eggs exhibit a large variability in the colour of their shell and the patterns that adorn them. Since the time of Charles Darwin, such traits have drawn the attention of numerous evolutionary ecologists fascinated by the variety of egg colours and patterns of pigmentation. The traditional explanation of this diversity of egg colouration is that it is the result of crypsis or strategies evolved to reduce intraclutch variation in order to avoid predators and/or broodparasites (for review, see Kilner 2006). However, more 
recently, new hypotheses accounting for the function of eggshell colouration and its inter-specific and intra-specific variability have been proposed. These hypotheses focus on both the background colour of the egg (i.e. the base colour; see Moreno and Osorno 2003) and maculation (i.e. pigmentation patterns). Gosler et al. (2005), Higham and Gosler (2006) and Jubb et al. (2006) have all recently presented solid non-experimental evidence that eggshell pigmentation patterning (eggshell maculation) in the Great Tit (Parus major) could be related to calcium availability and shell thickness. According to Gosler et al. (2005), pigment spots are located especially on thinner patches of the shell, and the pigmentation pattern (i.e. distribution of spots and intensity of pigmentation) is associated with variations in shell thickness. These authors suggest that protoporphyrins, the predominant eggshell pigments in speckled (maculate) eggs (Kennedy and Vevers 1976), are used to compensate for localized shell-thinning when calcium is scarce. Gosler et al.’s (2005) findings support the "structural function hypothesis" which argues that protoporphyrins act as a cushion or shock-absorber, increasing shell strength (Solomon 1987). Higham and Gosler (2006) suggested that maculation may reduce eggshell permeability (possibly, therefore, affecting the rate of water loss from the egg) during incubation in a process adjusted through female behaviour. The rate of water loss depends on shell thickness to a large extent, with thin-shelled eggs being indicative of calcium deficiency during egg formation (Ar et al. 1974; Graveland et al. 1994). Thus, Gosler et al. (2005) predicted that if pigments served a structural function, variation in the distribution ("spread") and in both the intensity and size ("darkness") of pigment spots should relate to eggshell mass and/or thickness as they found that pigment spots specifically demarcated thinner areas of shell, with darker spots marking yet thinner shell than paler spots. These authors also found that both the thickness of the eggshell and its pigmentation were highly related to the availability of calcium within a few hundred metres of the nest. Based on these findings, it follows that an effect of calcium availability on variation in both eggshell pigment "spread" and pigment "darkness" is to be expected.

An alternative, but not exclusive, hypothesis presented by Martínez-de la Puente et al. (2007) in a study using the Blue Tit (Cyanistes caeruleus) as a model species proposes that eggshell spottiness and colour reflect health and condition. These authors demonstrated a clear relationship between eggshell colour (background and spots) and female health and condition. They propose that due to the fact that protoporphyrins are pro-oxidative agents, their accumulation produces a physiological stress that is reflected in the higher deposition of pigment in eggshells. However, whether this deposition is an adaptation by laying females to diminish stress or whether it is simply an unavoidable consequence of stress in these females could not be disentangled by the authors. It is important to note that the accumulation of protoporphyrins within the context of this hypothesis is not expected to be especially related to the availability of calcium.

Calcium is an essential resource for passerine birds, especially during egg formation. These birds ("income breeders") do not store calcium for egg formation in the medullary bone, in contrast to such "capital breeders" as chickens, pigeons or waders, rather, they lay eggs on resources that are ingested very shortly before egg laying (Pahl et al. 1997). Up to $98 \%$ of the dry mass of the avian eggshell consists of a calcite lattice, which is a crystalline form of calcium carbonate (Reynolds et al. 2004). Thus, a shortage of this micronutrient during the egg-laying period could result in eggshell defects (e.g. eggs with thin and porous shells, deviant pigmentation, lack of a cuticle; see Drent and Woldendorp 1989; Graveland et al. 1994; Eeva and Lehikoinen 1995; Graveland 1996) and, therefore, a reduced hatching success due to excessive water loss or shell breakage. Evidence of calcium-limited reproduction has been found in acidified areas of central and western Europe (namely, the Netherlands, Czech Republic, Wales) and the Canadian Shield (for review, see Reynolds et al. 2004) and in naturally calcium-poor territories, such as pine forests on base-poor sandy and peat soils (e.g. Estonia, Fennoscandia block; see Tilgar et al. 1999). Impaired reproduction could reflect a reduced availability of calcium-rich items, such as calcareous grit (e.g. Krementz and Ankney 1995) or small snail shells, which are the main source of calcium for tits (Graveland and van Gijzen 1994; Perrins 1996; Graveland and Berends 1997). Snail abundance has been shown to be closely related to soil properties, such as soil $\mathrm{pH}$, or calcium content in the litter, since these invertebrates consume decaying plant materials to obtain the calcium necessary for shell growth (Johannsenn and Solhøy 2001; Martin and Sommer 2004; Jubb et al. 2006).

In the study reported here, we assessed the effect of a calcium supplementation experiment on the eggshell pigmentation pattern of three Blue Tit populations breeding in deciduous oak forests. Earlier observations on these populations revealed distinctive egg traits (shell quality, spotting, egg size), which could possibly reflect differences in calcium availability among these areas (authors, personal observation). Blue Tits lay eggs speckled with reddish spots (protoporphyrins) that are similar to those of Great Tits, a closely related species. We tested whether Blue Tit eggs laid by females provided with a supplementary calcium-rich material had a different pigmentation pattern (spot distribution and spot size, pigment intensity) or different physical properties (shell thickness) relative to those 
of control nests and whether the calcium supplementation affected some of the reproductive parameters (the length of the incubation period and reproductive success). Conforming to assumptions derived from Gosler et al. (2005), we predicted that calcium supplementation would increase eggshell thickness and/or decrease both the intensity and size of the protoporphyrin spots. To the best of our knowledge, this is the first time that associations found in previous correlative studies (Gosler et al. 2005; Sanz and García-Navas 2009) have been tested experimentally.

\section{Methods}

\section{Study area}

The study was carried out during the 2007 breeding season in three Pyrenean oak (Quercus pyrenaica) woodlands of central Spain. Two of the plots (Gil García and Valdeyerno) were located in Quintos de Mora (Toledo province, $39^{\circ} 25^{\circ} \mathrm{N} 4^{\circ} 04^{\circ} \mathrm{W}, 890 \mathrm{~m}$ a.s.l.), a government-owned game reserve. The third plot (Valsaín) was situated within the government-owned and protected area of Montes de Valsaín (Segovia province, $40^{\circ} 53^{\circ} \mathrm{N}, 4^{\circ} 01^{\circ} \mathrm{W}, 1200 \mathrm{~m}$ a.s.l.) where nest boxes have been available for holenesting passerines since 1991. The vegetation characteristics of these areas are different, largely due to the different browsing pressure that they support. In Quintos de Mora, large herbivores, such as red deer Cervus elaphus and to a lesser extent wild boar Sus scrofa, are abundant. The high deer density (40 individuals/100 ha) has a negative effect on forest regeneration and the degree of understory development (Álvarez and Ramos 1991; Sanz et al. 2010). In contrast, ungulates are absent or extremely rare in Valsaín which permits the existence of a well-developed undergrowth layer (mainly comprising sprouting oaks and Cistus laurifolius). More details about the study sites can be found in Sanz (2001) and Tornero (2003).

\section{Field protocol}

Frequent checks of nest boxes provided data on the date of clutch initiation, clutch size, hatching success and the number of fledged young. During the egg-laying period, the nests were visited daily with the aim of establishing the laying order (eggs were numbered with a felt-tip pen) and take a photograph (side view on a squared background with the aid of a small base) of each eggs for later scoring of the eggshell pigmentation pattern (see below). The length of the incubation period was defined as the number of days between completion of the clutch and hatching of the eggs (first observation of chicks during the daily visit). Parents (92 females and 85 males forming 80 pairs; Gil García: 19,
Valdeyerno: 22, Valsaín: 39) were captured on the third (Valsaín) or eight day (Gil García and Valdeyerno) after hatching. On capture, they were weighed with an electronic balance to the nearest $0.1 \mathrm{~g}$, their tarsus length was measured with a digital calliper to the nearest $0.01 \mathrm{~mm}$ and their wing length (maximum chord) was measured to the nearest $1 \mathrm{~mm}$ with a stopped ruler. On the 13th day after hatching, the nestlings were ringed and weighed, and their tarsi was measured in the same way as for adults.

\section{Calcium survey: land snail density}

In order to determine the presence/absence of gasteropod species and, if present, estimate snail density, we carried out a systematic snail survey prior to initiating the calcium supplementation treatment (mid-late April). We used a similar protocol to that employed in previous studies (Graveland and van der Wal 1996; Ramsay and Houston 1999). Snails in randomly chosen quadrats of $0.590 .5 \mathrm{~m}^{2}$, ten per study site, were collected. The samples contained the litter layer plus the top $5 \mathrm{~cm}$ of the mineral soil. The material was air-dried and searched by eye for land snails in the laboratory. The searching time per sample was about $30 \mathrm{~min}$. These data and our personal observations were collated by interviewing forest managers in both study areas.

\section{Calcium-provisioning experiment}

The calcium supplementation experiment was performed by attaching open feeding cups to the outside of nest boxes once birds had finished the nest-building period. In Gil García and Valdeyerno, following laying of the first egg, the feeders were filled with $1.0 \mathrm{~g}$ of a mixture of small fragments of snail shells and chicken white eggshell (50:50). The feeders were inspected daily, and the amount of calcium remaining was weighed with a field precision balance (Tanita Corp, Tokyo, Japan; accuracy $0.001 \mathrm{~g}$ ) to estimate calcium consumption. We added to the mixture each day (as necessary) to provide a surplus of $1.0 \mathrm{~g}$ of calcium-rich material per day until clutch completion. In Valsaín, however, feeders were supplemented with $4.0 \mathrm{~g}$ of big fragments of snail shells. This precluded any knowledge of the exact quantity of calcium consumed as birds probably consume only part of the shell fragments and throw away the rest. The mass of the fragments remaining at the feeder was weighed each day with a precision balance to the nearest $0.1 \mathrm{~g}$, and fragments of snails shells were added to reach $4.0 \mathrm{~g}$. As such, we were able to determine when calcium was consumed; that is, for this area, we created a binary variable: calcium consumption versus no consumption. Empty feeders attached to control nest boxes were used to control for the possible influence of the feeders per se on breeding traits. Calcium-supplemented and 
control nests were matched by laying date; consequently, there was no difference in breeding phenology between groups in any of the study areas (mean laying date, $1=1$ April; Gil García: 17.9, Valdeyerno: 20.5, Valsaín: 32.8; all P [ 0.5). Data on a total of 14 nest dyads in Gil García, 14 nest dyads in Valdeyerno and 23 nest dyads in Valsaín were ultimately collected. Treatments (calcium-supplemented group or control group) were distributed to avoid the consumption of calcium by birds from adjacent nest boxes without supplementation (Graveland and Drent 1997; Reynolds et al. 2004). To that end, nests of calcium-supplemented and control pairs were separated by a minimum distance of $100 \mathrm{~m}$.

Birds took time to get accustomed to the feeders. Cases of no calcium consumption during one or several days were frequent in the three populations, especially at the beginning of the laying period. The percentage of eggs for which we detected calcium intake on the day before laying was 73.2 and $59.6 \%$ in Gil García and Valdeyerno, respectively. Unfortunately, due to adverse weather conditions in Valsaín leading to rain-soaked feeders, the calcium-rich material could not be properly weighed daily in this area. We assume that birds bred in this population responded to calcium supplementation in a similar way as did those from the other areas. We also assume that the calcium contained in the feeders was eaten by females. Previous studies with captive birds have shown that males do not exhibit much interest in calcium-rich items since their calcium requirements are minimal compared with egg-laying females (e.g. Graveland and Berends 1997). Graveland and Berends (1997) found that there was a tenfold difference between males and females in the time invested in handling snail shells and that males rarely seemed to consume calciumrich items. Therefore, in our analysis, we neglected the male's calcium intake.

Data on calcium intake are presented as net mass, assuming a calcium content of 34\% (33\% for snail shell and $35 \%$ for egg shell following Graveland 1995) for the mixture that we provided to the birds.

\section{Scoring eggshell pigmentation}

Following Gosler et al. (2000), one observer (VGN) scored the eggshell pigmentation pattern of 941 eggs (corresponding to 102 clutches) on the basis of three categories: pigment intensity (I: scored in 0.5 increment units, from 1 for the palest spots to 5 for the darkest), average spot size (S: scored in 0.5 increment units, from 1 for small spots to 3 for large spots) and spotting distribution over the surface (D: scored in 0.5 increment units, from 1 for $[90 \%$ of spots concentrated at one end, to 5 for an even spot distribution). Eggshells were scored for pigment from photographs by researchers blinded to the experimental treatment. Because these three scoring variables are highly intercorrelated (Gosler et al. 2000), a principal components analysis (PCA) from the correlation matrix of $\mathrm{I}, \mathrm{D}$, and $\mathrm{S}$ values was performed on individual eggs to diminish the redundancy of the measures. The two principal components obtained, PC1 and PC2, accounted for 80.3\% of the total variance. The first principal component (PC1, 46.8\% of the total variation in I, D and S) described variation in pigment intensity and spot size ("darkness" of the egg; see Gosler et al. 2000) and showed higher values for eggs with larger and more reddish spots (factor loadings: I: 0.840, D: 0.209, S: 0.808). The second principal component (PC2, 33.5\% of the total variation in I, D and S) described the level of spot aggregation (the "spread" of maculation) and showed higher values for eggs with spots more widely distributed over their surface (factor loadings: I: 0.019, D: 0.965, S: 0.270). For a number of our analyses, our initial sample was reduced to 462 eggs due to data being disregarded for those eggs for which there was no evidence that calcium had been consumed by the laying female on the day preceding laying.

\section{Egg sampling}

Unhatched eggs (addled or infertile eggs, eggs from predated or deserted clutches) were collected to measure the thickness of the eggshell. These eggs, once removed, were stored in a refrigerator $\left(4^{\circ} \mathrm{C}\right)$ until analysed. The eggs were cut into two halves equatorially using a razor blade and then emptied. Empty shells were thoroughly wiped inside to remove the remaining albumen, and the inner egg membrane was removed using tweezers. We measured shell thickness (to $0.001 \mathrm{~mm}$ ) on the shoulder (broad pole region) of the egg (where hatching occurs) using a Mitutoyo (Mizonokuchi, Japan) digital micrometer. The mean of three measurements from the shoulder of the egg (including unpigmented and pigmented areas) was used in the analysis. We also measured the length and breadth of each egg with a digital caliper to obtain an egg shape index (breadth/length ratio) and egg volume following the equation described by Hoyt (1979). Due to small sample sizes in two areas (Valdeyerno, $\mathrm{n}=11$ eggs; Valsaín, $\mathrm{n}=6$ eggs), only eggs gathered in Gil García (27 eggs from 27 clutches; Ca-fed $=13$, control $=14$ ) were considered for further analyses.

\section{Statistical analyses}

The two treatments (Ca-supplemented vs. control) were compared using generalized linear models (GLMs). We tested whether (1) both eggshell pigmentation pattern ("darkness" and "spread") and thickness, (2) reproductive parameters (clutch size, length of incubation period, hatching and breeding success) and (3) measurements of 
nestling and adults differed between both groups in terms of treatment, study area and their interaction as factors and in terms of covariates: clutch size or brood size, laying order, egg shape and egg volume. All analyses were performed using clutch means, with the exception of those for eggshell thickness, which was performed from the unhatched sample of eggs. The effect of calcium provisioning on eggshell pigmentation pattern was also analysed by deriving clutch means only from the eggs for which there was evidence of calcium-rich material consumption by the laying-female on the day preceding laying and their equivalents (according to laying order) in control nests. Following the same procedure, we compared the hatching probability of eggs from Ca-supplemented and control nests (pairs matched according to laying date, LD) by means of a t test. We also tested for calcium supplementation effects on pigmentation pattern within the clutch (i.e. intra-clutch variation) by comparing, within calciumsupplemented nests, mean pigmentation values (PC1, PC2) obtained from those eggs for which we detected the consumption of calcium rich-material by the laying-female on the day prior to laying with those for which we did not.

Only the statistics from the final models (obtained by sequential removal of non-significant terms) are reported in the results. Post hoc comparisons were assessed with least significant difference (LSD) tests. To allow for the use of parametric tests, hatching (proportion of eggs hatched) and breeding success (proportion of eggs that resulted in fledged young) were arcsine square root-transformed. All values are presented as means \pm standard deviation (SD), unless stated otherwise.

\section{Results}

Differences in reproductive traits among populations

Our three Blue Tit populations showed different reproductive traits. When only control nests were considered, we found that Blue Tits breeding in Valsaín laid later (study site: $\mathrm{F}_{2,48}=12.81, \mathrm{P} \backslash 0.001$; Table 1) and had larger clutches (study site: $\mathrm{F}_{2,47}=7.66, \mathrm{P}=0.01$; laying date: $\left.\mathrm{F}_{1,47}=21.38, \mathrm{P} \backslash 0.001\right)$ than breeding pairs of Gil García and Valdeyerno. The length of the incubation period also varied significantly among areas (study site: $\mathrm{F}_{2,47}=3.28, \quad \mathrm{P} \backslash 0.05 ; \quad \mathrm{LD}: \mathrm{F}_{1,47}=11.87, \quad \mathrm{P}=0.01$; Table 1). Hatching success was lower for the Gil García population that for the populations in the other localities (study site: $\mathrm{F}_{2,48}=7.08, \mathrm{P} \backslash 0.01$, Table 1 ).

We also found differences in maculation among Blue Tit populations when only control nests were considered. The distribution of pigment spots was more marked (spots more concentrated at one end) for Gil García clutches than for those of Valdeyerno and Valsaín (P $\backslash 0.02$; Table 1). The percentage of eggs with a high level of spot aggregation at the blunt end (eggs with a "corona" ring; D B 2.5) was $30.2(\mathrm{n}=122), 5.7(\mathrm{n}=129)$ and $9.6 \%(\mathrm{n}=218)$ in Gil García, Valdeyerno and Valsaín, respectively. Blue Tits at Gil García also had the lowest values for both the size and intensity of pigment spots, although differences among the three populations were not statistically significant (P โ 0.2 in both cases).

\section{Calcium survey: land snail density}

Land snails were completely absent from both study areas. Despite intensive searching, we found no sign of gastropod species at any of the 30 quadrats sampled. Our observational data agree with personal communications by forest managers, who also have never detected presence of land snails in these forests.

Since calcium availability (or rather, the lack of it) seems to be homogeneous throughout all of our study sites and both areas are far from anthropogenic sources of calcium, there is no evidence that the nestbox populations of Blue Tits in our study may travel large distances to acquire calcium, such as has been shown for Great Tits in a recent study by Wilkin et al. (2009).

Table 1 Reproductive parameters and attributes of eggshell pigmentation in three Blue Tit (Cyanistes caeruleus) populations of central Spain

\begin{tabular}{lcrr}
\hline $\begin{array}{l}\text { Reproductive parameters/attributes } \\
\text { of eggshell pigmentation }\end{array}$ & Gil García $(\mathrm{n}=14)$ & Valdeyerno $(\mathrm{n}=14)$ & Valsaín $(\mathrm{n}=23)$ \\
\hline Laying date $(1=1$ April) & $17.86 \pm 13.9 \mathrm{a}$ & $20.57 \pm 9.24 \mathrm{a}$ & $32.60 \pm 5.68 \mathrm{~b}$ \\
Clutch size & $9.29 \pm 2.46 \mathrm{a}$ & $8.93 \pm 1.27 \mathrm{a}$ & $9.74 \pm 1.66 \mathrm{~b}$ \\
Incubation period (days) & $14.00 \pm 0.35 \mathrm{a}$ & $13.36 \pm 0.35 \mathrm{~b}$ & $13.83 \pm 0.27 \mathrm{a}$ \\
Hatching success & $71.28 \pm 4.11 \mathrm{a}$ & $85.32 \pm 4.11 \mathrm{~b}$ & $90.61 \pm 3.20 \mathrm{~b}$ \\
Intensity of pigment spots & $3.74 \pm 0.59$ & $3.91 \pm 0.34$ & $3.91 \pm 0.47$ \\
Spotting distribution & $3.22 \pm 0.97 \mathrm{a}$ & $3.73 \pm 0.52 \mathrm{~b}$ & $3.69 \pm 0.72 \mathrm{~b}$ \\
Spot size & $2.00 \pm 0.30$ & $2.08 \pm 0.34$ & $2.11 \pm 0.35$ \\
\hline
\end{tabular}

Only control nests $(n=51)$ are included. Numbers of clutches are given in brackets

Values are given as the mean \pm standard error $(\mathrm{SE})$. Values followed by different letters are statistically significant $(\mathrm{P} \backslash 0.05)$ 
Calcium provisioning experiment

The average calcium intake during the entire egg laying period was 238.5 (32.5 per egg) and $148.9 \mathrm{mg}$ (17.9 mg per egg) in Gil García and Valdeyerno, respectively. The daily calcium consumption increased on the day after the females laid eggs with defective shells (thin-shelled, with deviant pigmentation; authors, personal observation). In Gil García, the percentage of eggs with spots concentrated at the blunt end was significantly smaller for Ca-supplemented nests than for control nests when both entire clutches were taken into account (Ca-fed: 19.3\%, control: $35.7 \%$; chi-square test $\mathrm{v}_{1}^{2}=3.68, \mathrm{P}=0.049$ ) as well as only those eggs laid after calcium consumption and their equivalents in laying order for control nests (Ca-fed: 8.6\%, control: 37.9\%; chi-square test $\left.\mathrm{v}_{1}^{2}=8.81, \mathrm{P} \backslash 0.01\right)$. There were no significant differences between these groups for the other two populations (all P $\mathbf{0} 0.05$ ).

In terms of pigmentation patterning, we did not find statistically significant differences between Ca-supplemented and control groups in pigment intensity and spot size or spotting distribution when entire clutches were considered (Table 2). When only those eggs laid after calcium intake and their equivalents were considered in the analysis, we did not observe a significant effect of calcium supplementation on the eggshell pigmentation "darkness"
Table 2 Differences in eggshell attributes (pigmentation pattern and thickness) and breeding parameters between calciumsupplemented (Ca-fed) and control nests
* Significant at $\mathrm{P} \backslash 0.05$

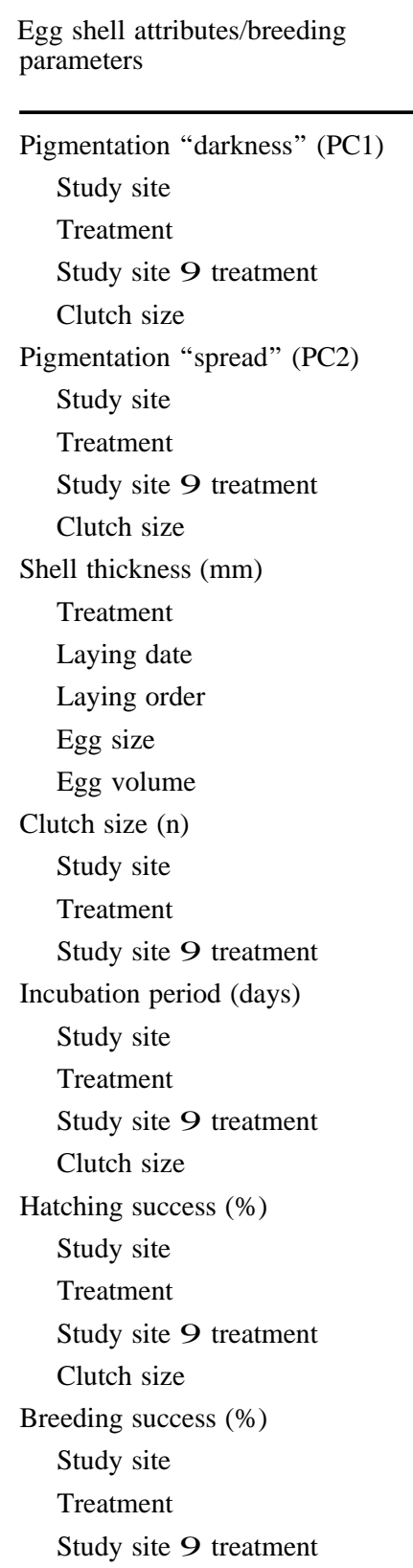

\begin{tabular}{|c|c|c|c|c|}
\hline \multicolumn{2}{|l|}{ Treatment } & \multirow[t]{2}{*}{$\mathrm{df}$} & \multirow[t]{2}{*}{$\mathrm{F}$} & \multirow[t]{2}{*}{$\mathrm{P}$} \\
\hline Ca-fed & Control & & & \\
\hline \multirow{5}{*}{$0.02 \pm 0.08$} & $-0.06 \pm 0.08$ & & & \\
\hline & & 2.99 & 5.12 & $\backslash 0.01 *$ \\
\hline & & 1.95 & 0.38 & 0.54 \\
\hline & & 2.95 & 0.34 & 0.71 \\
\hline & & 1.95 & 0.02 & 0.88 \\
\hline \multirow[t]{5}{*}{$-0.03 \pm 0.09$} & $-0.00 \pm 0.09$ & & & \\
\hline & & 2.99 & 3.91 & $0.02 *$ \\
\hline & & 1.95 & 0.06 & 0.81 \\
\hline & & 2.95 & 0.78 & 0.46 \\
\hline & & 1.95 & 0.60 & 0.44 \\
\hline \multirow{6}{*}{$0.067 \pm 3.27$} & $0.053 \pm 3.02$ & & & \\
\hline & & 1.24 & 10.37 & $\backslash 0.01 *$ \\
\hline & & 1.21 & 0.06 & 0.81 \\
\hline & & 1.21 & 0.96 & 0.34 \\
\hline & & 1.21 & 2.47 & 0.13 \\
\hline & & 1.24 & 6.73 & $0.02 *$ \\
\hline \multirow{4}{*}{$9.18 \pm 0.25$} & $9.32 \pm 0.25$ & & & \\
\hline & & 2.96 & 2.18 & 0.12 \\
\hline & & 1.96 & 0.15 & 0.70 \\
\hline & & 2.96 & 1.62 & 0.20 \\
\hline \multirow{5}{*}{$13.07 \pm 0.18$} & $13.73 \pm 0.18$ & & & \\
\hline & & 2.95 & 0.40 & 0.67 \\
\hline & & 1.100 & 8.06 & $\backslash 0.01 *$ \\
\hline & & 2.95 & 0.97 & 0.38 \\
\hline & & 1.95 & 1.12 & 0.30 \\
\hline \multirow{5}{*}{$84.78 \pm 2.12$} & $82.40 \pm 2.12$ & & & \\
\hline & & 2.99 & 19.30 & $\backslash 0.01 *$ \\
\hline & & 1.95 & 0.57 & 0.45 \\
\hline & & 2.95 & 0.34 & 0.71 \\
\hline & & 1.95 & 0.85 & 0.36 \\
\hline \multirow[t]{4}{*}{$78.07 \pm 2.70$} & $76.52 \pm 2.70$ & & & \\
\hline & & 2.99 & 25.24 & $\backslash 0.01 *$ \\
\hline & & 1.95 & 0.23 & 0.63 \\
\hline & & 1.95 & 4.40 & 0.07 \\
\hline
\end{tabular}




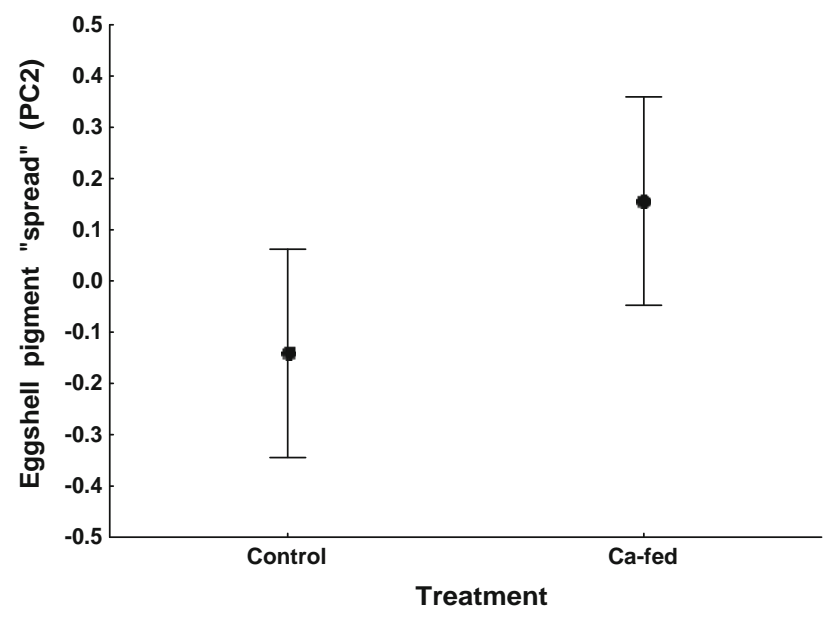

Fig. 1 Differences in eggshell pigmentation "spread” (PC2) between calcium-supplemented (Ca-fed; $n=51)$ and control nests $(n=51)$ from three Blue Tit (Cyanistes caeruleus) nest-box populations of central Spain. Means \pm standard error (SE) are presented

(PC1; Ca-fed: $-0.05 \pm 0.10$, control: $0.11 \pm 0.10$; GLM study site: $\mathrm{F}_{2,95}=2.79, \mathrm{P}=0.07$; treatment: $\mathrm{F}_{1,95}=$ 1.19, $\mathrm{P}=0.28$; treatment 9 study site: $\mathrm{F}_{2,95}=1.60$, $\mathrm{P}=0.21$; CS: $\left.\mathrm{F}_{1,95}=0.51, \quad \mathrm{P}=0.48\right)$, but we did observed an effect on eggshell pigmentation "spread" (PC2; GLM study site: $\mathrm{F}_{2,95}=1.45, \mathrm{P}=0.24$; treatment: $\mathrm{F}_{1,100}=4.19, \mathrm{P}=0.04$; treatment 9 study site: $\mathrm{F}_{2,95}=$ 1.16, $\mathrm{P}=0.32$; $\mathrm{CS}: \mathrm{F}_{1,95}=0.40, \mathrm{P}=0.52$ ). Eggs from supplemented nests showed a more homogeneous distribution of pigment spots over the eggshell surface than did control nests (Fig. 1). With respect to intra-clutch variation in pigmentation values within supplemented nests, we found that those eggs for which we detected calcium intake by the laying-female prior to laying had pigment spots that were more widely distributed over the eggshell in comparison with those eggs for which we did not observed calcium intake by the laying-female (pigmentation "spread", PC2; Ca-fed: $-0.39 \pm 1.15$, control: $0.06 \pm$ 0.59 , $\mathrm{t}$ test; $\left.\mathrm{t}_{70}=-2.11, \mathrm{P}=0.04\right)$. Within the same clutch, the intensity and size of the pigment spots did not differ significantly between eggs laid by laying-females who had or had not consumed calcium (pigmentation “darkness”, PC1; Ca-fed: $-0.29 \pm 1.30$, control: $0.05 \pm$ 0.60 ; $\mathrm{t}$ test; $\left.\mathrm{t}_{70}=-1.45 ; \mathrm{P}=0.15\right)$.

The thickness of the eggshell was also affected by the calcium supplementation treatment. In Gil García, the eggshells of eggs laid in Ca-supplemented nests were thicker than for those laid in control ones (Table 2). Otherwise, eggshell thickness increased with egg volume $(0.48 \pm 0.18)$.

Mean clutch size was not affected by the calcium supplementation treatment (Table 2). However, we did detect an effect of calcium provisioning on the length of the incubation period, with the incubation periods in
Ca-supplemented nests shorter than those in control nests (Table 2).

Hatching success did not differ between Ca-supplemented and control nests when entire clutches were considered in the analysis (Table 2). However, we found a significant difference in hatching success between both groups, including only those eggs for which laying females ingested calcium the preceding day and the equivalents in laying sequence (i.e. egg number) for control nests (Ca-fed: $92.9 \pm 0.11 \%$, control: $83.7 \pm 0.19 \%$; $t$ test: $t_{100}=2.74$, $\mathrm{P} \backslash 0.01)$.

Supplemented pairs did not raise more young than control pairs (Table 2). We detected no significant effect of calcium supplementation on nestling condition and there were no differences between Ca-supplemented and control broods in nestling body mass, tarsus length or wing length (see Table 3). There was also no significant difference in relation to female and male body parameters (body mass, tarsus length) between treatments (Table 3).

\section{Discussion}

As far as we are aware, this study is the first to experimentally test the role of calcium availability in determining eggshell pigmentation pattern in speckled eggs. The "structural function hypothesis" proposed by Solomon (1987, 1997) and findings from several correlative studies (Gosler et al. 2005; Higham and Gosler 2006; Jubb et al. 2006; Jagannath et al. 2008; Sanz and García-Navas 2009) suggest the existence of a correlation between eggshell pigmentation and eggshell thickness mediated by calcium acquisition. Specifically, Gosler et al. (2005) found in a British population of Great Tits nesting across a strong soil calcium gradient that the local calcium availability predicted both eggshell thickness and pigmentation between clutches. They also found an association between pigment deposition and thinner shelled areas, and pigment "darkness" and degree of thinning. Gosler et al.'s (2005) findings reinforce the view that protoporphyrins form an integral part of the shell matrix, sharing the same protein carrier as calcium ions, as suggested by Solomon (1987, 1997).

According to Solomon's hypothesis, protoporphyrins are responsible for eggshell maculae and could also act as lubricants, thereby strengthening the shell, which could be important in calcium-poor habitats where protoporphyrins may compensate for localized shell-thinning (Gosler et al. 2005). Therefore, if spots were to be associated with thinner areas, we should also expect to find an effect of calcium supplementation on the spot size and intensity, with lower values for eggs from experimental nests as compared to those from control nests. However, contrary to 
Table 3 Measurements of nestlings (Ca-fed $n=49$, control $n=50)$ and adults (female: Ca-fed $n=45$, control $n=47$; male: Ca-fed $n=43$, control $n=42$ ) in Ca-fed and control treatments
* Significant at $\mathrm{P} \backslash 0.05$

Measurements are given as the mean \pm standard deviation

\begin{tabular}{|c|c|c|c|c|c|}
\hline & \multicolumn{2}{|l|}{ Treatment } & \multirow[t]{2}{*}{ df } & \multirow[t]{2}{*}{$\mathrm{F}$} & \multirow[t]{2}{*}{$\mathrm{P}$} \\
\hline & Ca-fed & Control & & & \\
\hline Nestling body mass (g) & $10.73 \pm 0.12$ & $10.75 \pm 0.12$ & & & \\
\hline Study site & & & 2.92 & 2.27 & 0.11 \\
\hline Treatment & & & 1.92 & $\checkmark .01$ & 0.95 \\
\hline Study site 9 treatment & & & 2.92 & 0.16 & 0.85 \\
\hline Brood size on day 13 & & & 1.92 & 6.24 & $0.02 *$ \\
\hline Nestling tarsus length (mm) & $15.86 \pm 0.06$ & $15.86 \pm 0.07$ & & & \\
\hline Study site & & & 2.96 & 16.4 & ○.001* \\
\hline Treatment & & & 1.92 & $\backslash 0.01$ & 0.95 \\
\hline Study site 9 treatment & & & 2.92 & 0.41 & 0.66 \\
\hline Brood size on day 13 & & & 1.92 & 0.84 & 0.36 \\
\hline Nestling wing length (mm) & $40.53 \pm 0.37$ & $39.85 \pm 0.37$ & & & \\
\hline Study site & & & 2.96 & 9.95 & \.001* \\
\hline Treatment & & & 1.92 & 1.75 & 0.19 \\
\hline Study site 9 treatment & & & 2.92 & 0.37 & 0.69 \\
\hline Brood size on day 13 & & & 1.92 & 0.15 & 0.69 \\
\hline Female body mass (g) & $9.81 \pm 0.08$ & $9.84 \pm 0.08$ & & & \\
\hline Study site & & & 2.88 & 3.18 & $0.046^{*}$ \\
\hline Treatment & & & 1.84 & 0.04 & 0.83 \\
\hline Study site 9 treatment & & & 2.84 & 2.07 & 0.13 \\
\hline Female tarsus length & & & 1.84 & 2.86 & 0.09 \\
\hline Female tarsus length (mm) & $16.30 \pm 0.08$ & $16.27 \pm 0.09$ & & & \\
\hline Study site & & & 2.86 & 2.74 & 0.08 \\
\hline Treatment & & & 1.86 & 0.06 & 0.80 \\
\hline Study site $\mathbf{9}$ treatment & & & 2.86 & 1.38 & 0.26 \\
\hline Male body mass (g) & $10.01 \pm 0.07$ & $10.12 \pm 0.08$ & & & \\
\hline Study site & & & 2.79 & 5.77 & \.01* \\
\hline Treatment & & & 1.75 & 0.76 & 0.38 \\
\hline Study site 9 treatment & & & 2.75 & 0.90 & 0.41 \\
\hline Male tarsus length & & & 1.75 & 2.93 & 0.09 \\
\hline Male tarsus length (mm) & $16.53 \pm 0.08$ & $16.68 \pm 0.09$ & & & \\
\hline Study site & & & 2.79 & 2.68 & 0.07 \\
\hline Treatment & & & 1.79 & 1.49 & 0.22 \\
\hline Study site 9 treatment & & & 2.79 & 0.82 & 0.44 \\
\hline
\end{tabular}

predictions, eggshell pigment “darkness" did not differ significantly between the control and Ca-fed groups. The intensity and size of the spots did not vary as markedly as did the distribution pattern ("spread") over the shell surface, and this could be related to the high genetic component of PC1 (heritable on the female line), as shown by Gosler et al. (2000) for Great Tits. In addition to genetic inheritance, the absence of a significant effect of calcium supplementation on PC1 could be due to other factors not directly affected by calcium supplementation, such as female health status and physiological stress, that potentially affect eggshell maculation in Blue Tits (Martínez-de la Puente et al. 2007).
We did, however, find a relationship between the spread of the pigment spots and the availability of calcium to the female. The provision of calcium-rich material during the egg-laying period had an effect on the distribution of pigments spots, which largely determines hatching probability and thus can be viewed as an indicator of egg quality (Sanz and García-Navas 2009). We found that supplemented females laid eggs with spots that were more widely distributed over the shell surface than those of the control group. Furthermore, considering only supplemented nests, within the same clutch we observed statistically significant differences in the degree of spottiness between those eggs laid immediately after calcium consumption by the 
laying-female and those laid by females which had not ingested calcium. This difference is presumably due to the fact that females in most insectivorous and granivorous birds must collect calcium on a daily basis for egg production (Graveland and van Gijzen 1994; Perrins 1996; Graveland and Berends 1997; Pahl et al. 1997). We detected an immediate effect (from 1 day to the next) of calcium provisioning on eggshell pigmentation patterning, similar to that shown by Graveland and Berends (1997). Thus, there was a close relationship between variations in spot distribution through the laying sequence and the calcium intake pattern. Cases of no consumption (gaps in the calcium intake) or low amounts of calcium items taken by birds coincided with minimum values in eggshell quality (eggs with aberrant pigmentation, shells lacking a cuticle), after which the calcium intake increased noticeably (authors, personal observation).

In Gil García, we observed that calcium supplementation reduced the proportion of eggs with defective shells. It should be mentioned that in an earlier study we obtained evidence indicating that in some woodlands of Montes de Toledo (Quintos de Mora, Cabañeros National Park), reproduction in Blue Tit populations could be limited by calcium deficiency (Sanz and García-Navas 2009). Specifically, in the above-mentioned population of Gil García, we have found eggs with defective shells (aberrant pigmentation, dull and rough surface), females incubating empty nests, nestlings with broken or deformed leg-bones and a low hatching success (2006: 70\%). Most of these traits have not been previously been reported in the other two areas (Valdeyerno and Valsaín; authors, personal observation; Martínez-de la Puente et al. 2007) where the proportion of eggs with deviant pigmentation was significantly smaller than that in Gil García (see "Results"). Thus, the absence of an effect of calcium provisioning on the proportion of eggs with defective shells for the Valdeyerno and Valsaín populations was according to expectations. In this context, previous studies have shown the inefficiency of calcium supplementation experiments when birds are able to satisfy the demand for this micronutrient from their natural food (Johnson and Barclay 1996; Ramsay and Houston 1999). In our case, the differences found in egg traits between the Gil García and Valdeyerno populations are striking because these two study sites are only separated by $8 \mathrm{~km}$. A possible explanation for this difference could be that Blue Tits breeding in Gil García lay earlier than those in Valdeyerno and may not be able to obtain food with a high calcium content at the beginning of the breeding season. Another possibility is that this result emerges as result of differences in habitat traits (forest maturity, vegetation structure) linked to an unequal browsing pressure on these forests. In our study areas, soil arthropods (woodlice Diplopoda spp., millipedes
Isopoda spp.) would constitute the main calcium source for insectivorous passerines (Graveland and van Gijzen 1994) since in none of these localities have we detected the presence of litter dwelling snails. The underlying geology (relatively acidic bedrock; granites and gneisses in Montes de Valsaín and quartzite in Quintos de Mora) and the leaf litter of these oak woodlands (where calcium content of the foerna is bound to oxalate, a less soluble salt) inhibit the occurrence of land molluscs (Wäreborn 1969). Cervid hervibory causes well-known effects on plant species composition and architecture (e.g. Gill and Beardall 2001), but it may also lead to indirect trophic interactions since vegetation provides a habitat and a food supply for a considerable diversity of invertebrate species, and the timing of breeding and the reproductive performance of many passerine birds depends on insect abundance and their phenology (Stewart 2001; Gill and Fuller 2007; Spitzer et al. 2008). Such preys constitute an important protein and calcium source for egg production (e.g. Ramsay and Houston 2003). Hence, deer browsing may reduce the breeding success of birds through a series of knock-on effects at two other levels of the forest community (Pedersen et al. 2007). In fact, in a nearby study area (Cabañeros National Park), we have found a negative correlation between the spread of the eggshell pigmentation patterning and the distance of nests with respect to areas were deer were excluded by means of fences (i.e. ungrazed plots; distance to ungulate exclosure: $\mathrm{F}_{1,78}=4.04, \mathrm{P}=$ $0.04, \mathrm{~b}=-0.21$; laying date: $\mathrm{F}_{1,78}=6.51, \mathrm{P}=0.01$ ). Regrettably, no data on insect are available, and thus further research is needed to establish a casual pathway between browsing pressure and breeding success of birds in these areas.

Clutch size was not affected by our experiment. Based on the results of a long-term study, Tilgar et al. (1999, 2002) reported that the effects of calcium supplementation experiments on certain reproductive parameters (especially those subject to strong physiological constraints, such as clutch size) could vary largely from 1 year to the next according to environmental factors (e.g. yearly variations in weather conditions or food supply). Thus, we recommend caution in interpreting our results. However, calcium supplementation did indeed affect the length of the incubation period. In a cross-fostering study, Higham and Gosler (2006) found an association between eggshell colouration and incubation behaviour in female Great Tits. We found that female Blue Tits experimentally supplied with calcium-rich material had shorter incubation periods than control females. In a previous correlational study (Sanz and García-Navas 2009), we found a significant association between the length of the incubation period and spot distribution. Both results could be correlated with the fact that eggs with deviant pigmentation and thin and 
porous shells show high rates of mass loss (Graveland et al. 1994; Sanz and García-Navas 2009). The thickness of the eggshell was also affected by the calcium supplementation experiment; eggs from Ca-supplemented nests had thicker shells than those from control ones. A similar result was also found for Great Tits and Pied Flycatchers Ficedula hypoleuca in experimental studies carried out in Estonia (Mänd et al. 1999; Tilgar et al. 1999). A possible consequence of this thicker shell in our study was that the proportion of eggs that failed to hatch due to shell breakage or desiccation was smaller in Ca-supplemented nests. On the other hand, given that the feeders were removed after clutch completion and thus chicks were not fed with extra calcium (in contrast to Tilgar et al. 2002; Mänd and Tilgar 2003), the nestling condition did not differ between Ca-supplemented and control nests. This is in contrast to the results reported by Sanz and García-Navas (2009) who found an association between spotting distribution and nestling tarsus length.

To the best of our knowledge, this the first study carried out in Spain showing experimental evidence of calciumlimited reproduction in birds despite the fact that parts of the Iberian Peninsula have the lowest values of exchangeable calcium in Western Europe (Patten 2008 and references therein). Our results reinforce the view that pattern of spottiness constitute a reliable indicator of eggshell weakness (Gosler et al. 2005; Sanz and García-Navas 2009). The reason why calcium-deficient birds tend to lay eggs with spots concentrated around the broad end remains unclear. In light of the "structural function hypothesis" proposed by Solomon (1987, 1997), Gosler et al (2005) have suggested that protoporphyrins are especially deposited in thin patches of shell where calcium is scarce. However, we did not find eggs with a smaller spot size when we provided the birds with extra calcium. Our data suggest that the quantity of protoporphyrins deposited in the eggshells may not reflect the availability of calcium to laying-females; thus, pure white eggs cannot always be considered as the better egg morphotype with respect to calcium. Therefore, our work does not provide experimental support for the concept that eggshell pigment acts to reinforce the shell in those places where calcium deposition is less intense (Solomon 1987; Gosler et al. 2005). Further research is needed to improve our knowledge on the mechanisms of pigment deposition and physiological processes driving the maculation phenomenon.

In conclusion, based on our results, experimental calcium supplementation increases eggshell thickness and hatching success and decreases incubation period and eggshell defects. Despite our study being limited to a 1-year period (see recommendations given in Reynolds et al. 2004), our findings show that eggshell pigment "spread" of Blue Tit eggs is a relatively plastic trait sensitive to environmental conditions experienced by breeding females during the egg formation period (see also Martínez-de la Puente et al. 2007 for a similar conclusion with respect to eggshell pigmentation). Studies reporting on the "spread" maculation of eggs gathered from different European populations (i.e. along a soil calcium gradient) will provide information relating to the extent that calcium deficiency represents a limiting factor for shell formation in the Paridae.

\section{Zusammenfassung}

Experimenteller Nachweis der Bedeutung von Kalzium für das Pigmentierungsmuster der Eischale und die Fortpflanzungsleistung von Blaumeisen Cyanistes caeruleus

Vorherige Studien haben starke Zusammenhänge zwischen der Verfügbarkeit von Kalzium und der Pigmentierung der Eischale bei Kohlmeisen (Parus major) festgestellt. Der „strukturellen Funktionshypothese” zufolge werden Protoporphyrine, die Pigmente, die für die rötlichen Punkte auf gesprenkelten Eiern verantwortlich sind, in den Bereichen der Schale abgelagert, in denen die Ablagerung von Kalzium weniger stark ist. In dieser Studie, die in drei Populationen der Blaumeise (Cyanistes caeruleus) in Zentralspanien durchgeführt wurde, liefern wir teilweise experimentelle Unterstützung für den Zusammenhang zwischen Protoporphyrin-Pigmentierung und Ausdünnung der Eischale. Entgegen unserer Erwartungen beobachteten wir keine Abnahme der Größe und Intensität der Pigmentflecken auf Eiern aus Nestern von Brütern, die zusätzliches Kalzium erhielten. Wir fanden jedoch, dass das Bereitstellen kalziumreichen Materials während der Legephase zu einer ausgedehnteren Verteilung der Pigmentflecken führte und den Anteil von Eiern mit fehlerhaften Schalen (abweichende Pigmentierung, matte und raue Oberfläche) reduzierte. Wenn nur die mit Kalzium versorgten Nester in Betracht gezogen wurden, fanden wir auch Unterschiede in der Verteilung der Flecken zwischen Eiern, für die wir eine Aufnahme von Kalzium am Tag vor der Eiablage beobachten konnten, und Eiern desselben Geleges, für die das nicht der Fall war. Die Gelegegröße wurde durch die Bereitstellung von Kalzium nicht beeinflusst. Weibliche Blaumeisen, die experimentell mit kalziumreichem Material versorgt wurden, hatten eine kürzere Bebrütungsphase als Kontrollweibchen. Die Dicke der Eischale wurde ebenfalls durch die Bereitstellung von Kalzium beeinflusst; Eier aus mit Kalzium versorgten Nestern hatten dickere Schalen als Eier aus Kontrollnestern. Die Dicke der Eischale beeinflusst die Schlupfwahrscheinlichkeit merklich und könnte den niedrigeren 
Anteil ungeschlüpfter später Eier in mit Kalzium versorgten Nestern im Vergleich mit Kontrollnestern erklären. Diese Studie hebt die Rolle von Kalzium in der Pigmentierung der Eischale und seine Effekte auf die Fortpflanzungsleistung kleiner Sperlingsvögel hervor. Wir haben gefunden, dass die Verteilung der Flecken Kalziummangel gut vorherzusagen scheint. Andererseits stützen unsere Ergebnisse die „strukturelle Funktionshypothese” nur zum Teil, da die Dicke der Eischale eng mit der Verfügbarkeit von Kalzium verbunden ist, während der Zusammenhang zwischen Kalzium und der Ablagerung von Protoporphyrinen alles andere als klar ist.

Acknowledgments V. García-Navas thanks J. V. Ruiz-Peinado his valuable assistance during the fieldwork. We are indebted to J. M. Sebastián and C. Rodríguez Vigal (Quintos de Mora) and J. Donés (Montes de Valsaín) for permission to work in these protected areas. Permits to capture and ring adults and nestlings were obtained from Dirección General del Medio Natural (Junta de Castilla-La Mancha) and Consejería de Medio Ambiente (Junta de Castilla y León). We are grateful to Andy Gosler for many insightful comments that helped to improve a previous version. This study was funded by projects 69/ 2003 (MMA), CGL2006-14129-C02-01/BOS (MEC) and CGL200761251 (MEC) to J. J. Sanz, S. Merino and J. Moreno, respectively. V. García-Navas was partially supported by a grant from Diputación de Toledo. J. Martínez-de la Puente was supported by a grant from “El Ventorrillo"-CSIC. E. Lobato benefited from a FPU grant (MEC). This study is a contribution from the field station "El Ventorrillo".

\section{References}

Álvarez G, Ramos J (1991) Estrategias alimentarias del ciervo (Cervus elaphus L.) en Montes de Toledo. Doñ Act Vert 18:6399

Ar A, Paganelli CV, Reeves RB, Greene DG, Rahn H (1974) The avian egg: water vapour conductance, shell thickness, and functional pore area. Condor 76:153-158

Drent PJ, Woldendorp JW (1989) Acid rain and eggshells. Nature 339:431

Eeva T, Lehikoinen E (1995) Egg shell quality, clutch size and hatching success of the Great Tit (Parus major) and the pied flycatcher (Ficedula hypoleuca) in an air pollution gradient. Oecologia 102:312-323

Gill RMA, Beardall V (2001) The impact of deer on woodlands: the effects of browsing and seed dispersal on vegetation structure and composition. Forestry 74:209-218

Gill RMA, Fuller RJ (2007) The effects of deer browsing on woodland structure and songbirds in lowland Britain. Ibis 149:119-127

Gosler AG, Barnett PR, Reynolds SJ (2000) Inheritance and variation in eggshell patterning in the Great Tit Parus major. Pro R Soc Lond B 267:2469-2473

Gosler AG, Higham JP, Reynolds SJ (2005) Why are birds' eggs speckled? Ecol Lett 8:1105-1113

Graveland J (1995) The quest for calcium: calcium limitation in the reproduction of forest passerines in relation to snail abundance and soil acidification. Ph.D. thesis. University of Wagenigen, Wageningen

Graveland J (1996) Avian eggshell formation in calcium-rich and calcium-poor soils: importance of snail shells and anthropogenic calcium sources. Can J Zool 74:1035-1044
Graveland J, Berends AE (1997) Timing of the calcium intake and effect of calcium deficiency on behaviour and egg laying in captive Great Tits, Parus major. Physiol Zool 70:74-84

Graveland J, Drent RH (1997) Calcium availability limits breeding success of passerines on poor soils. J Animal Ecol 66:279-288

Graveland J, van der Wal R (1996) Decline in snail abundance due to soil acidification causes eggshell defects in forest passerines. Oecologia 105:351-360

Graveland J, van Gijzen T (1994) Arthropods and seeds are not sufficient as calcium sources for shell formation and skeletal growth in passerines. Ardea 82:299-314

Graveland J, van der Wal R, van Balen JH, van Noordwijk AJ (1994) Poor reproduction in forest passerines from decline of snail abundance in acidified soils. Nature 368:446-448

Higham JP, Gosler AG (2006) Speckled eggs: water-loss and incubation behaviour in the Great Tit Parus major. Oecologia 149:561-570

Hoyt DF (1979) Practical methods of estimating volume and fresh weight of bird egg. Auk 96:73-77

Jagannath A, Shore RF, Walker LA, Ferns PN, Gosler AG (2008) Eggshell pigmentation indicates pesticide contamination. J Appl Ecol 45:133-140

Johannsenn LE, Solhøy T (2001) Effects of experimentally increased calcium levels in the litter on terrestrial snail populations. Pedobiology 45:234-242

Johnson LS, Barclay RMR (1996) Effects of supplemental calcium on the reproductive output of a small passerine, the House Wren (Troglodytes aedon). Can J Zool 74:278-282

Jubb M, Gosler AG, Wilkin TA (2006) Eggshell-pigmentation, soil calcium and the local abundance, distribution and diversity of woodland snails (Mollusca). Ardea 94:1-12

Kennedy GY, Vevers HG (1976) A survey of avian eggshell pigments. Comp Biochem Physiol 55B:117-123

Kilner R (2006) The evolution of egg colour and patterning in birds. Biol Rev 81:383-406

Krementz DG, Ankney CD (1995) Changes in total body calcium and diet of breeding house sparrows. J Avian Biol 26:162-167

Mänd R, Tilgar V (2003) Does supplementary calcium reduce the cost of reproduction in the Pied Flycatcher Ficedula hypoleuca? Ibis 145:67-77

Mänd R, Tilgar V, Leivits A (1999) Calcium, snails and birds: a case study. Web Ecol 1:63-69

Martin K, Sommer M (2004) Relationships between land snail assemblage patterns and soil properties in temperate-humid forest ecosystems. J Biogeogr 31:531-534

Martínez-de la Puente J, Merino S, Moreno J, Tomás G, Morales J, Lobato E, García-Fraile S, Martínez J (2007) Are eggshell spottiness and colour indicators of health and condition in Blue Tits Cyanistes caeruleus? J Avian Biol 38:377-384

Moreno J, Osorno JL (2003) Avian egg colour and sexual selection: does eggshell pigmentation reflect female condition and genetic quality? Ecol Lett 6:803-806

Pahl R, Winkler DW, Graveland J, Batterman BW (1997) Songbirds do not create long-term stores of calcium in their legs prior to laying: results from high-resolution radiography. Proc R Soc Lond B 264:239-244

Patten MA (2008) Geographic variation in calcium and clutch size. J Avian Biol 38:637-643

Pedersen S, Nilsen EB, Andreassen HP (2007) Moose winter browsing affects the breeding success of great tits. Écoscience 14:499-506

Perrins CM (1996) Eggs, egg formation and the timing of breeding. Ibis $138: 2-15$

Ramsay SL, Houston DC (1999) Do acid rain and calcium supply limit eggshell formation for Blue Tits (Parus caeruleus) in the U.K.? J Zool 247:121-125 
Ramsay SL, Houston DC (2003) Amino acid composition of some woodland arthropods and its implications for breeding tits and other passerines. Ibis 145:227-232

Reynolds SJ, Mänd R, Tilgar V (2004) Calcium supplementation of breeding birds: directions for future research. Ibis 146:601-614

Sanz JJ (2001) Experimentally increased insectivorous bird density results in a reduction of caterpillar density and leaf damage to Pyrenean oak. Ecol Res 16:387-394

Sanz JJ, García-Navas V (2009) Eggshell pigmentation pattern in relation to breeding success of Blue Tits (Cyanistes caeruleus). J Anim Ecol 78:31-41

Sanz JJ, García-Navas V, Ruiz-Peinado JV (2010) Effect of habitat type and nest site features on the breeding performance of great and blue tits in a Mediterranean landscape. Ornis Fenn 87 (in press)

Solomon SE (1987) Egg shell pigmentation. In: Wells RG, Belyarin CG (eds) Egg quality—current problems and recent advances. Butterworths, London, pp 147-157

Solomon SE (1997) Egg and eggshell quality. Iowa State University Press, Ames

Spitzer L, Konvicka M, Benes J, Tropek R, Tuf IH, Tufova J (2008) Does closure of traditionally managed open woodlands threaten epigeic invertebrates? Effects of coppicing and high deer densities. Biol Conserv 141:827-837

Stewart AJA (2001) The impact of deer on lowland woodland invertebrates: a review of the evidence and priorities for future research. Forestry 74:259-270

Tilgar V, Mänd R, Leivits A (1999) Effect of calcium availability and habitat quality on reproduction in Pied Flycatcher Ficedula hypoleuca and Great Tit Parus major. J Avian Biol 30:383-391

Tilgar V, Mänd R, Mägi M (2002) Calcium shortage as a constraint of reproduction in Great Tits Parus major: a field experiment. J Avian Biol 33:407-413

Tornero J (2003) Los Quintos de Mora. Ministerio de Medio Ambiente, Madrid

Wäreborn I (1969) Land mollusc and their environment in an oligotrophic area in southern Sweden. Oikos 20:461-479

Wilkin TA, Gosler AG, Garant D, Reynolds SJ, Sheldon BC (2009) Calcium effects on life-history traits in a wild population of the Great Tit (Parus major): analysis of long-term data at several spatial scales. Oecologia 159:463-472 